Supplement of Atmos. Chem. Phys. Discuss., 15, 35383-35415, 2015

http://www.atmos-chem-phys-discuss.net/15/35383/2015/

doi:10.5194/acpd-15-35383-2015-supplement

(C) Author(s) 2015. CC Attribution 3.0 License.

(c) (i)

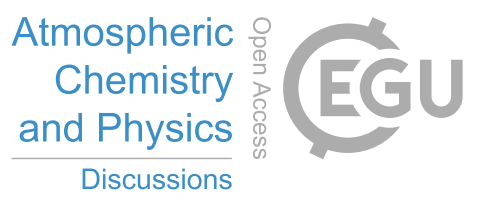

Supplement of

\title{
Size distribution and mixing state of black carbon particles during a heavy air pollution episode in Shanghai
}

\section{Gong et al.}

Correspondence to: X. Yang (yangxin@fudan.edu.cn)

The copyright of individual parts of the supplement might differ from the CC-BY 3.0 licence. 
1 1. SP2 data analysis and a way to enhance the LEO-fit accuracy

2 The SP2 data were analyzed using PSI v4.100 (Martin Gysel, Paul Scherrer Institute, 5232

3 Villigen, Switzerland) for the IGOR Pro software package (Wavemetrics, Inc., Portland, OR,

4 USA).

5 The small particles are not necessarily heated to full incandescence in SP2. Therefore, one can

6 get a peak that is smaller than it should be for a small mass of BC because the particle is not

7 getting sufficiently hot. Furthermore, a high-gain on the narrowband detector, as used in this

8 work, can introduce a decrease for the smallest particle sizes. The color ratio could possibly help

9 with this issue. The color ratio was calculated from the ratio of the broadband to narrowband

10 signals (Moteki and Kondo, 2010). We excluded BC-containing particles with color ratio in

11 excess of 3.0 from analysis. This improved the LEO-fit accuracy, especially for small core

12 BC-containing particles.

13

14 Table S1. Symbols and abbreviations

\begin{tabular}{|l|l|}
\hline Symbol or abbreviation & Meaning \\
\hline BC & Black carbon \\
\hline$D_{c}$ & The black carbon core diameter \\
\hline$D_{\mathrm{p}}$ & The entire particle diameter \\
\hline$D_{\text {ME }}$ & Mass equivalent diameter \\
\hline$D_{\text {va }}$ & The vacuum aerodynamic diameter \\
\hline SP2 & Single-particle soot photometer \\
\hline SPAMS & Single particle aerosol mass spectrometer \\
\hline sccm & Standard-state cubic centimeter per minute \\
\hline ACT & Absolute coating thickness \\
\hline RCT & Relative coating thickness \\
\hline
\end{tabular}




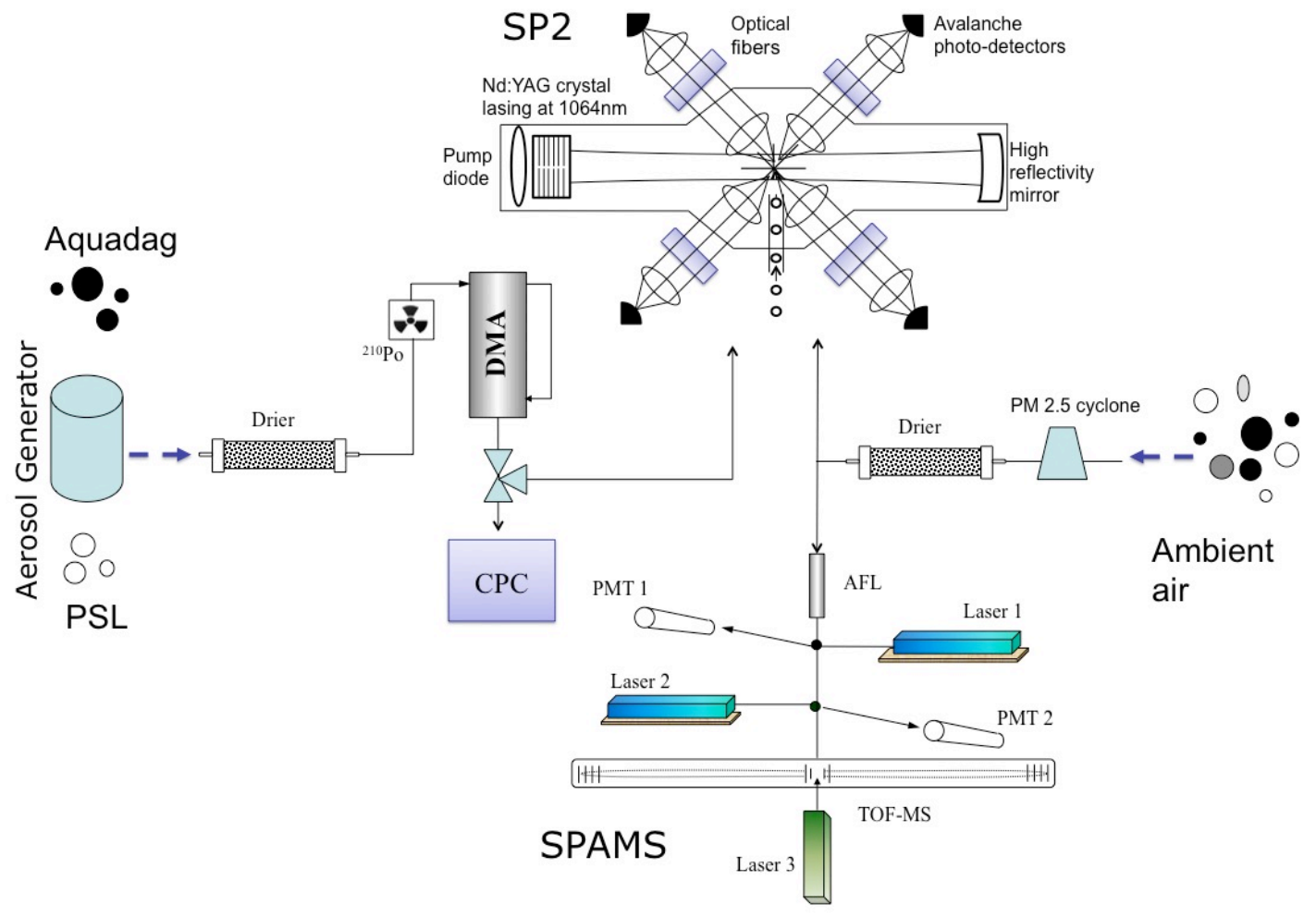

16

17 Figure S1. A schematic diagram of the calibration and measurement system. The DMA, CPC,

18 SP2 and SPAMS represent Differential Mobility Analyzer, Condensation Particle Counter,

19 Single Particle Soot Photometer, and Single Particle Aerosol Mass Spectrometer, respectively. 


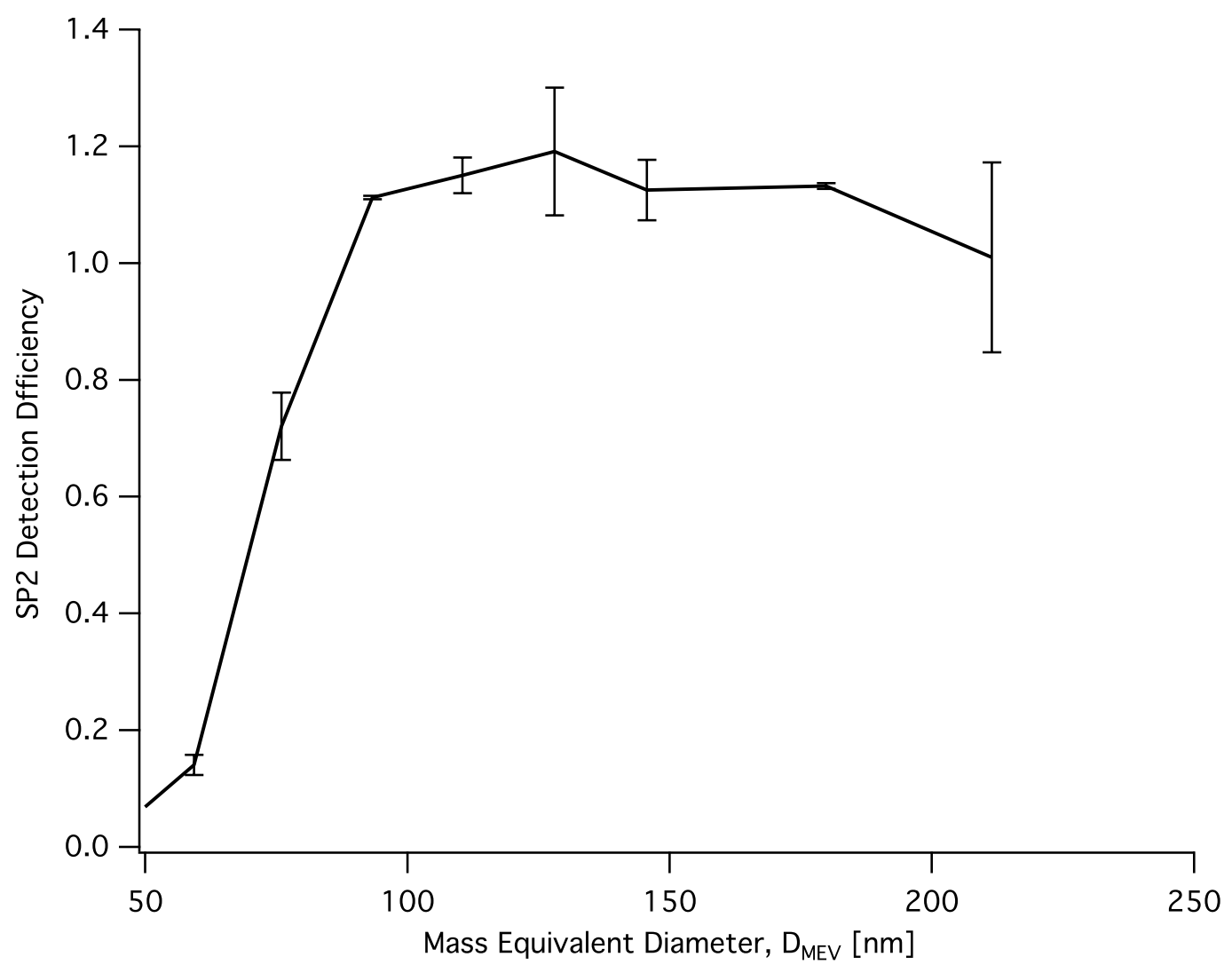

21 Figure S2. The average detection efficiencies in each BC size-bin at fixed laser intensity 22 (1750 mA). Whiskers represent the standard deviation of the values in each size bin. In 23 order to understand the mass and number size distribution of ambient $\mathrm{BC}$ particles, here 24 we transformed the mass equivalent diameter $\left(\mathrm{D}_{\mathrm{MEV}}\right)$ of Aquadag $^{\circledR} \mathrm{BC}$ to $\mathrm{D}_{\mathrm{MEV}}$ of 25 ambient $\mathrm{BC}$ according to their mass and different density 


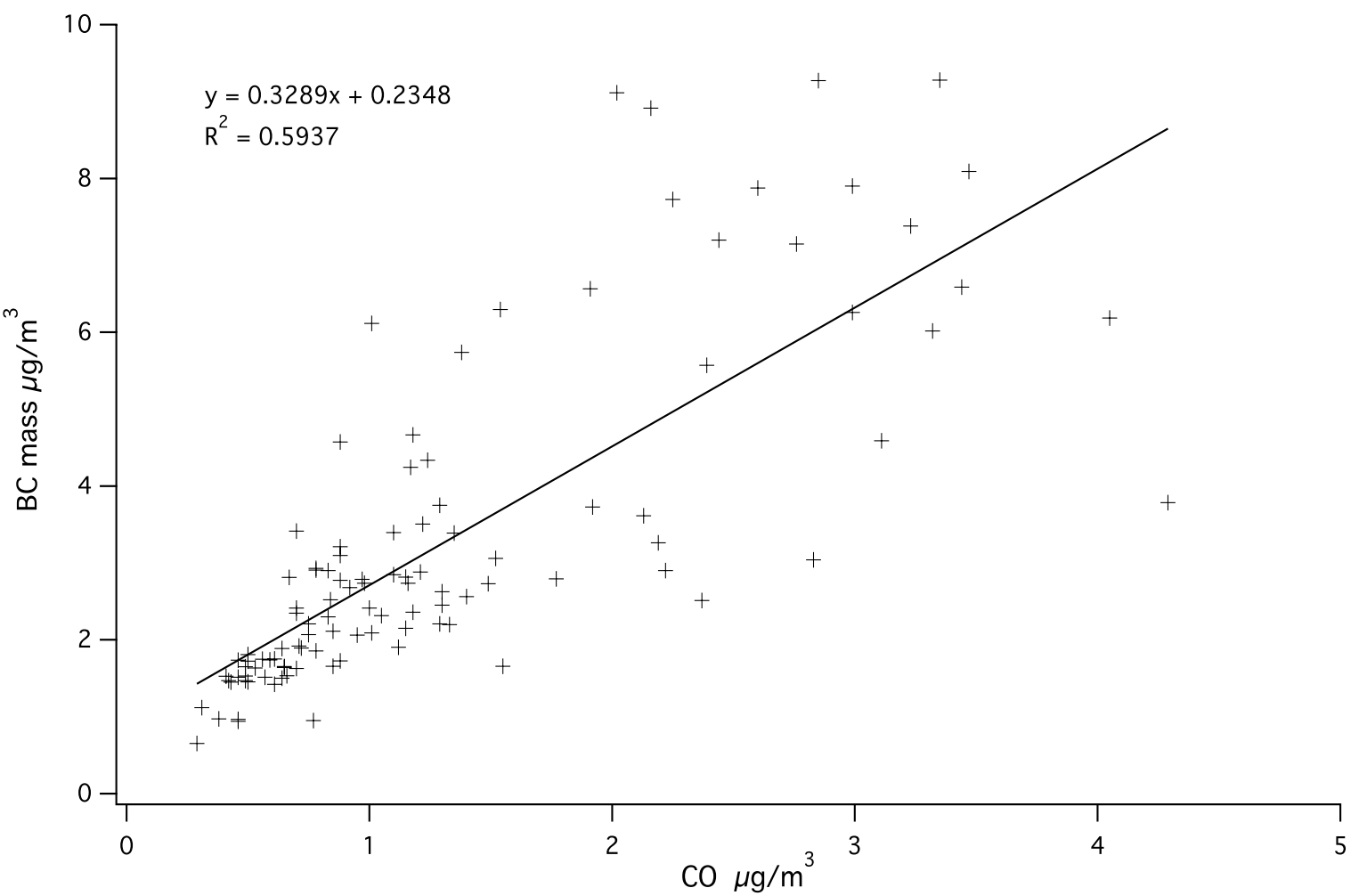

27 Figure S3. A comparison between the measured $\mathrm{CO}$ and $\mathrm{BC}$ mass concentration. 
30
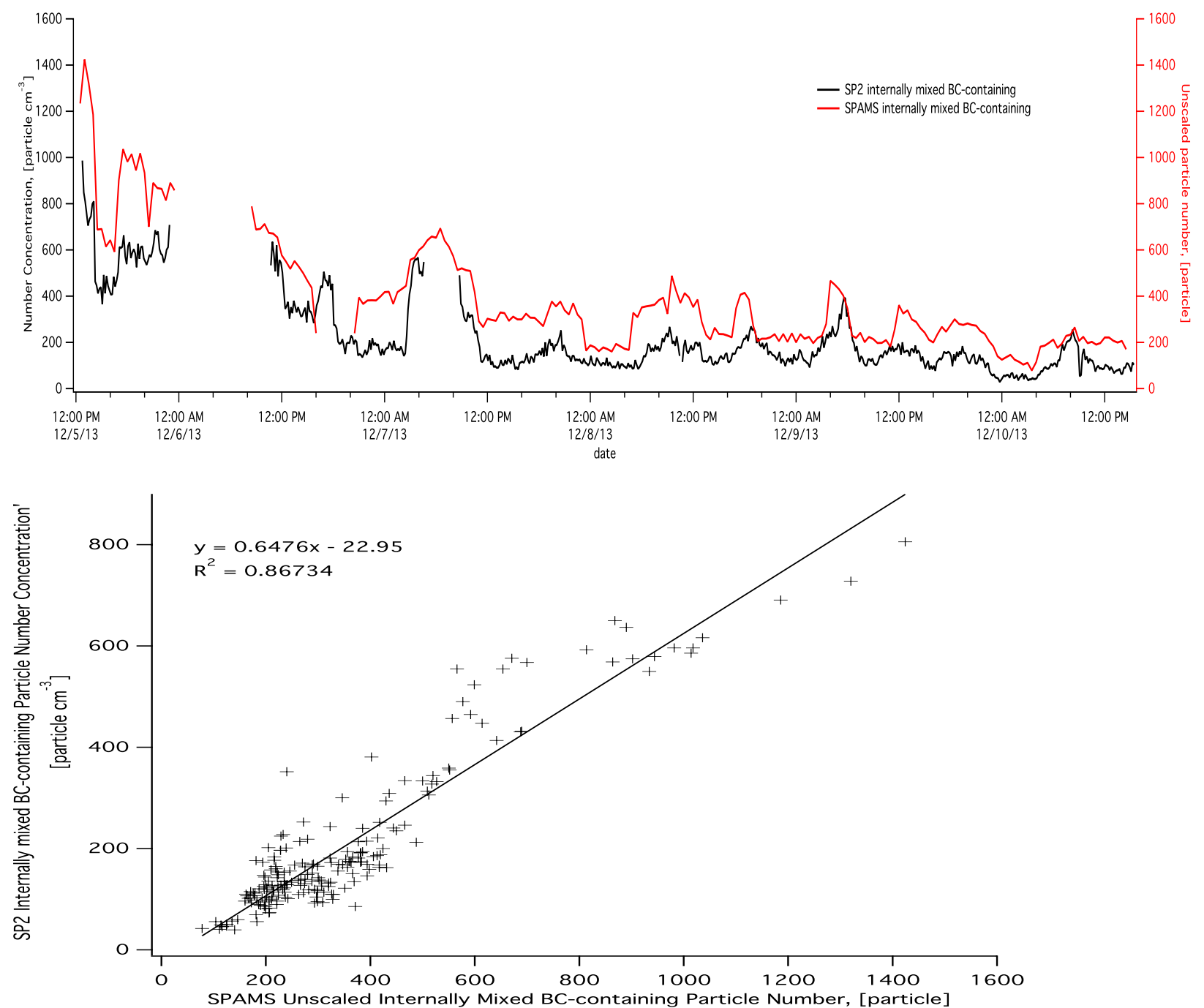

31

32 Figure S4. A comparison of the SPMAS-detected and SP2-detected internally-mixed 33 BC-containing particles. 

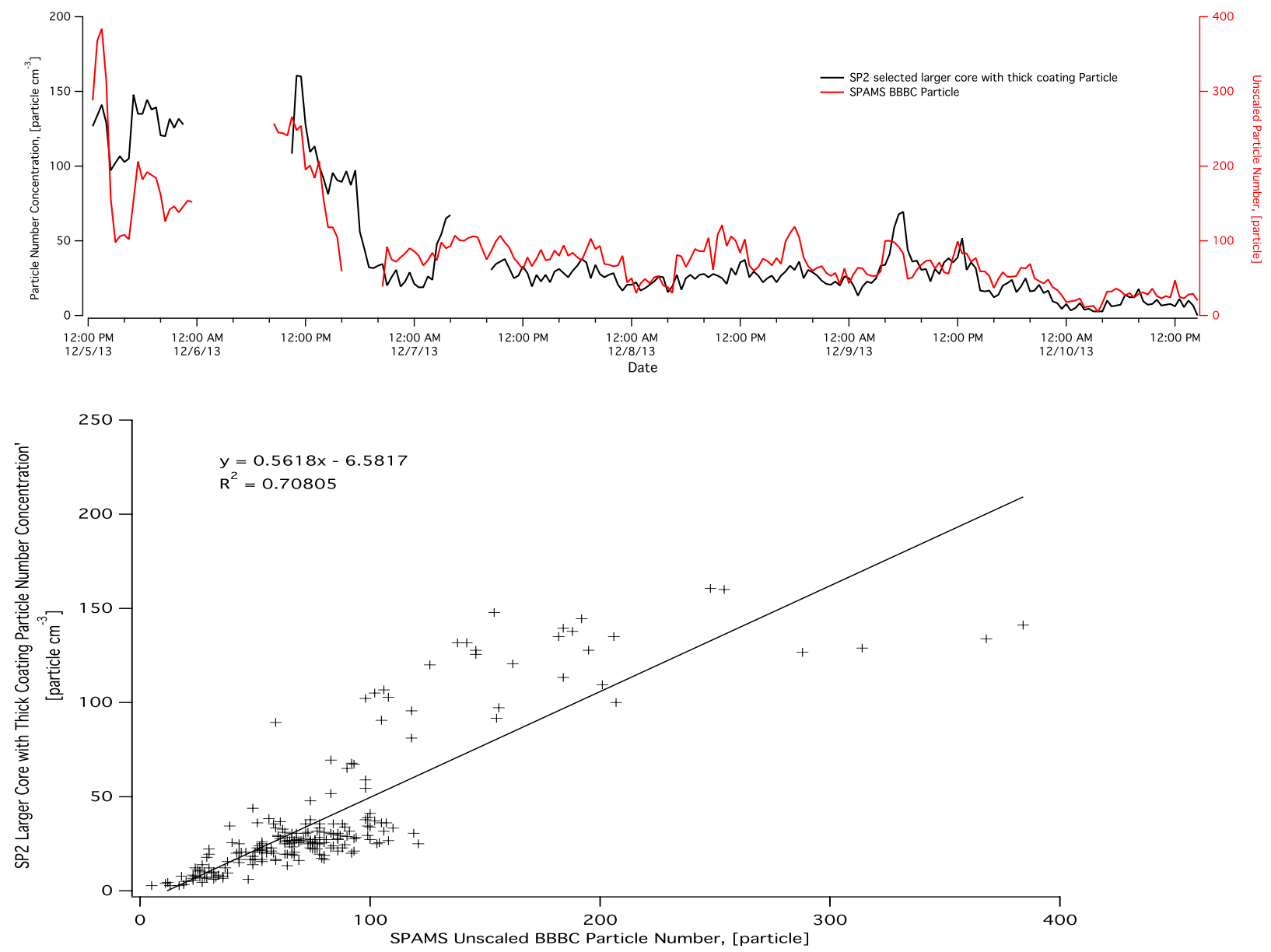

38 Figure S5. A comparison of the SPMAS-detected and SP2-detected biomass burning 39 BC-containing particles.

40

\section{References}

42 Moteki, N., and Kondo, Y.: Dependence of laser-induced incandescence on physical 43 properties of black carbon aerosols: Measurements and theoretical interpretation, Aerosol 44 Sci. Technol., 44, 663-675, 2010.

45 